\title{
Thoracic Outlet Syndrome
}

National Cancer Institute

\section{Source}

National Cancer Institute. Thoracic Outlet Syndrome. NCI Thesaurus. Code C85188.

A syndrome resulting from the compression of the blood vessels or nerves in the space between the clavicle and first rib (thoracic outlet). It is caused by car accident injuries or repetitive job or sport-related injuries. Signs and symptoms include pain in the shoulders and neck, numbness in the fingers, and weakening grip. 